\title{
Racismo hoy: un fruto del irracionalismo ilustrado
}

\author{
Magdalena M. Holztrattner
}

Rodríguez Bobb, Arturo (2005), El negro, el colonialismo y la política racial europea. Aspectos cognitivos asociados a la violencia racional. Frankfurt am Main et al.: editorial Peter Lang / Europäischer Verlag der Wissenschaften, 340 páginas, ISBN: 3-631-54706-4

- ste libro intenta retratar el de- sarrollo intelectual europeo y estadounidense de los siglos XVIII y XIX mediante sus representantes más sobresalientes, desde los más importantes filósofos de la edad antigua y paleocristiana. El autor, además, sigue el planteamiento de cómo pensaron y escribieron estos intelectuales sobre personas de piel negra y qué intenciones persiguieron con sus discursos científicos, para demostrar la irracionalidad intelectual que hasta hoy sirve como razón para el racismo del mundo occidental.

El autor, un sociólogo colombiano que trabaja en la Universidad 
Libre de Berlín, critica la razón de la Ilustración confrontando sus planteamientos con sus prácticas y diagnostica "una constitución de conciencia enferma que, advertida por una experiencia histórica en relación con la esclavitud de los africanos, no tolera el optimismo ni la autonomía del no europeo" (105). Esta estructura del pensamiento "no es comprensible dentro de una conciencia moderna, humana, sino que ella es localizable dentro de los intereses políticos de reflexiones polémicas" (104): Los intereses políticos y económicos marcan, aunque de manera disfrazada, el discurso sobre la importancia de la población negra y esclava, respectivamente, dentro del sistema político e intelectual del mundo occidental de los siglos XVIII y XIX. El ego cogito de la llustración se desenmascara como ego conquino (yo conquisto), que la cultura occidental impone - hasta hoy en día- a la vida y al pensamiento de "los demás" como norma normans mortífera.

El trabajo de Rodríguez Bobb es una relectura de la Ilustración europea desde el punto de vista de la población negra esclavizada y marginada, respectivamente. El autor investiga los fundamentos de la Ilustración, las conclusiones racionales platónicas y aristotélicas como también argumentos bíblicos y paleocristianos en relación a personas humanas negras. Demuestra el racismo de la temprana filosofía social europea y francesa en textos de, entre otros, Voltaire, Montesquieu,
Rousseau. También escruta a pensadores ingleses como Locke, Smith y Hume, entre otros. Rodríguez Bobb describe el desarrollo, desde el etnocentrismo hasta el eurocentrismo pasando por el nacionalsocialismo, con ejemplos de filósofos alemanes como Herder, Kant, Hegel Humboldt, entre otros, para después dirigir la mirada sobre el Atlántico hacia los EE.UU. para demostrar el razonamiento intelectual de algunos presidentes de los EE.UU. respecto a la población negra en el discurso sobre los pro y contra de la esclavitud, para, en base de eso, Ilegar a conclusiones para el presente.

En esta investigación ética-filosófica el autor trata la problematización transcultural del racismo y de la violencia racista en países occidentales - también en el presente- refiriéndose a textos de autores centrales de la llustración bajo el punto de vista de cómo se nombra o argumenta la marginación de la población negra (esclava). Los textos tienen en común querer probar con argumentos racionales la inferioridad de la gente que no es blanca y sometida para preservar la supremacía de los pueblos, es decir, de los señores blancos, respectivamente, para así garantizar la explotación económica de las personas negras en las plantaciones. Para eso se tenía que comprobar que personas de piel negra no son, en el sentido pleno, seres humanos o tienen condiciones intelectuales menores que las personas, específicamente que los hombres de piel blanca. 
Las lineas de argumentación que demuestra el autor, llevan a la conclusión justificada que "no toda razón será bienvenida. Dado que en la conciencia ilustrada analizada, no existe razón que pueda ocuparse de ella misma, con respecto a las personas de piel negra esclavizadas $y$, dado que toda conciencia ilustrada tiene que elegir su lugar en el entramado de prepotencias y antipotencias, los medios para dar validez a la esclavitud de las personas de piel negra parecen, incluso, más importante que la razón misma" (315).

En el área de la interculturalidad, el autor escribe no solamente con autoridad científica, sino también personal, pues no solo ha estudiado e investigado los dos puntos de vista sino también ha experimentado prejuicios y limitaciones basadas en pensamiento racista en su trabajo científico cotidiano durante su permanencia en Alemania.

Lo especial de esta monografía es el panóptico amplio de textos ilustrativos, tomados de filósofos europeos y estadounidenses, que son iluminados bajo un punto de vista que apenas hasta ahora se ha tomado en cuenta. Como crítica, hay que decir que Rodríguez Bobb inserta largas citas directas, que ha tomados de literatura secundaria - sobre todo de un autor en particular - sin acompañarlas de una introducción o de una explicación. Además la lectora se pregunta por qué no ha reemplazado el atributo "europeo" del título principal con "occidental", ya que en una buena parte de la monografía se deja hablar a voces de EE.UU, en otras palabras, la limitación geográfica que propone el título no se refleja en la obra misma. El autor no presta atención al aspecto de género, que toma un papel importante tanto en el trato teórico como también práctico de la población negra, ni tampoco investiga la pregunta del trato de los pueblos indígenas de los continentes americanos por los poderes coloniales europeos, a pesar que se esperaría por lo menos un párrafo al respecto en esta buena obra científica.

\section{Resumen:}

Se ve la relevancia para la filosofía intercultural del planteamiento enfocado en esta monografía: Investiga desde afuera - desde el punto de vista de la población negra y de los y las descendientes de las personas negras esclavizadas —la historia intelectual europea de los siglos XVIII y XIX para explicar el fondo intelectual del racismo y de la violencia racista, que todavía está activa, frente a personas que no son de piel blanca en los países occidentales. Esta mirada "desde los márgenes" puede ayudar a disminuir futuras faltas —en la política y la política del desarrollo de Estados occidentales- e irradia la esperanza de aprender de las faltas del pasado (colonial) de países europeos. Pues, solamente si es consciente de sus errores del pasado, Europa puede contribuir a un mundo globalizado en que el color de piel 
ya no es una razón, ni racional ni justificada, para la marginalización política, social y económica de una parte de la población.

"Sin duda [...] la teoría racista elaborada por el pensamiento occidental no tiene nada que ver con la existencia de razas biológicas objetivas pero si muestra que el pensamiento racista de los intelectuales aquí analizado es un producto histórico o cultural, obviando el equívoco de las explicaciones posmodernistas que, por otra vertiente, tienden también a convertir o a relativizar estas actitudes racistas "cultas" en elemento invariable de la naturaleza humana." (305)
La monografía presentada logra dar una contribución importante para seguir la pista de un racismo furtivo dentro del pensamiento y la argumentación personal y estatal, pues, la actitud intelectual y política de una sociedad occidental (blanca) frente a sus compatriotas de otro color de piel es un sismógrafo fino para medir la calidad de una democracia.

Magdalena M. Holztrattner teóloga, investigadora de pobreza y pedagoga becaria de la Academia Austríaca de Ciencias de la Universidad de Salzburgo (en cooperación con UCA El Salvador) Magdalena. Holztrattner@sbg.ac.at

\section{Fe de errata}

En el número 110 de Realidad se afirma que Olga Vásquez, autora del ensayo "Cristologías liberadoras. Una aproximación al pensamiento de Jon Sobrino y Elizabeth Schussler", pertenece al Departamento de Teología de nuestra universidad, dato que es completamente erróneo. Rogamos las disculpas del caso. 